\title{
THE SOVEREIGN CREDIT DEFAULT SWAP MARKET - IS THERE ANYTHING TO BE AFRAID OF? A COMPARISON OF SELECTED CENTRAL AND WESTERN EUROPEAN ECONOMIES
}

The paper concentrates on the impact of sovereign CDS (sCDS) on other financial markets within a country, and tests whether the impact changed after imposing the ban on trade of the non-covered sCDS in Europe (November 2012). The European sCDS of Poland, Hungary, and the Czech Republic (emerging markets) as well as Sweden and the United Kingdom (developed markets) are analysed over the period of 2008-2013. We investigate the influence between the sCDS and the foreign exchange market, sCDS and sovereign bonds, as well as sCDS and stock exchanges. The results vary depending on the liquidity and maturity of the analysed markets, indicating that the Central European markets used to be more prone to sunspots and volatility transmission than the Western ones. The study suggests that in most cases the impact of the CDS on other financial markets diminished after November 2012 and that the markets of speculative investment grade contributed most to the ban. test

Keywords: CDS, financial crisis, volatility, VAR, GARCH, Granger causality test, Hong

JEL Classifications: C32, C58, G15, G18

DOI: $10.15611 /$ aoe.2019.2.06

\section{INTRODUCTION}

Sovereign CDS spreads are a measure commonly associated with the risk of the country's solvency. Buyers of the sovereign bond protect themselves against the so-called credit event (e.g. delay in payment of accruals, declining to pay, etc.), through entering sCDS contracts. They regularly pay the sellers of the sCDS a pre-specified amount, the so-called premium or spread, expressed in base points. In the case of the credit event, the seller of sCDS pays the buyer the amount pre-specified in the contract.

The underlying instrument of sovereign CDS is the government bond. Up to 2012, the buyer of the sCDS was not obliged to have sovereign bonds. Thus, the instruments could be used to simply speculate on government default. With the outbreak of the Greek crisis, such speculators were blamed

\footnotetext{
* Department of Applied Mathematics, Poznań University of Economics and Business.
} 
for raising the cost of the issuers of government debts - including the Greek debt itself (see also: Augustin 2014). Consequently, the legislators in the European Parliament and the Council issued a new regulation, which came into force on 1 November 2012. According to this Regulation (EU No. 236/2012) it is forbidden to enter short position in uncovered sovereign debt through the CDS contract in the European Union (ISDA 2014).

This decision has been widely criticised by market analysts and investors because of its negative impact on the sCDS market liquidity (ISDA 2014). In Western Europe, the volume traded dropped by as much as $50 \%$, while in Central Europe - by $40 \%$. Market participants who wanted to assess the sovereign risk of a given country started to use other indices (e.g. iTraxx Europe Senior Financials) instead of sCDS spread (ibidem).

The aim of this research is to examine whether the new regulation heavily influenced the interrelations between the sCDS market and other financial markets within the same country. We analyse five different markets: Sweden and the United Kingdom (safe and developed), Hungary (risky and developing), as well as Poland and the Czech Republic (still developing but less risky). The main criterion of the choice was whether the countries retained their own currencies up to the end of 2013, since one of the analysed financial markets was the foreign exchange market. The others were sovereign bonds and the stock exchange markets. This study extends the research by Kliber (2016) who analysed changes in the dynamic conditional correlation between sCDS and the domestic financial markets in Hungary and Sweden, as well as Kliber (2017).

Most of the studies on the CDS market concentrate on determining what exactly drives the CDS premium. However, the decision of the legislators to regulate the sCDS trade and ban speculations suggests that they could have been afraid of the negative impact the market could have on the overall rating of the economies. The goal of this paper is to check up whether this fear was justified in the sense that the changes of sCDS spreads could affect other financial markets within a country, and if so, whether this impact diminished once the new regulation came into force.

The relationships between sCDS and the sovereign bonds market have already been widely studied in the literature, but the results are ambiguous. Fontana and Scheicher (2010 and 2016) documented that before September 2008 no lead-lag relationship was present between sCDS and the bond markets, while afterwards such relationships appeared but their direction was country-specific. According to Coudert and Gex (2011), the direction of a lead-lag relationship between the two markets depended on whether the 
bonds were of a low or high yield. Arce et al. (2011) examined, inter alia, the impact of the banks' agreements to accept losses on their holdings of Greek bonds during the Greek crisis. They concluded that the ability of the sCDS market to lead the price discovery process was impaired by this decision. Kliber (2012) found that, among others, in the case of low-yield countries like Finland and Denmark the influence of the Greek crisis was undistinguishable from the first phase of financial turmoil, and that the relationships between the bond and sCDS markets were broken due to the Greek crisis only in Greece and France. Eventually, Capponi and Larsson (2014) analysed the consequences of the ban on SCDS speculation (November 2012) on the bond markets, through developing a partial equilibrium model. They demonstrated that if the investors are risk-averse and take relatively small positions when compared to the amount of outstanding debt, the ban should have only a minor effect on the bond market.

The exact relationship between the yields of sovereign bonds and sCDS spreads has not been specified. Depending on the situation, we can observe either positive or negative correlations. For instance, Fontana and Scheicher (2016), when referring to the model of Merton (1974), postulate that the correlation should be negative. On the other hand, other researchers note that in the period of distress the spread between the yields of a given country's bonds and the least risky ones becomes wider (see e.g. Jain, 2014). As investors prefer safe assets, the yield of safe bonds lowers, while the yield of the risky ones grows. At the same time the sCDS spreads also grow. As a result, the correlation between the yield of risky sovereign bonds and SCDS spreads should be positive (see also: Niedziółka, 2009, chapter 13.4 for the discussion on this issue).

There are also articles analysing interrelations between CDS and the stock exchange markets. Coronado et al. (2012) studied causality and correlation between sCDS and the stock markets in Mediterranean Europe, Ireland, Germany, and France. The authors found that in general the stock market led the sCDS market, but starting from 2010 the relation changed in riskier countries of Southern Europe and in Ireland. The results were partially confirmed by De Silva (2014) who found that CDS spreads did not Granger cause stock index returns in Finland and France, and that the degree of causality was very low for Austria and the Netherlands. Together with downgrades and credit quality deterioration in Portugal, Italy, France, Germany, Finland, Belgium, Austria, and the Netherlands, the magnitude of the effects from the stock market on the CDS market lessened. The author 
claimed that the relationships in volatility were more stable during tranquil periods. Eventually, according to Platev and Marinova (2013), for Russia and Poland the index return caused changes in sCDS spread (in Granger's sense), while for Hungary, Romania, and Bulgaria the relationships were the opposite.

Significantly fewer studies were devoted to the causality relationships between sCDS and the foreign exchange markets. Breuer and Sauter (2012) analysed the impact that the European market credit event exerts on the Euro-Dollar exchange rate. Carr and $\mathrm{Wu}$ (2007) studied the markets in Mexico and Brazil and came up with an analysis of covariance between sovereign CDS and implied volatility of currency options, as well as its slope in moneyness. Della Corte et al. (2014) analysed developing and developed markets all over the world and showed that an increase in the sovereign risk of a country is associated with a depreciation of its currency and an increase in exchange rate volatility. They claimed that this link was largely driven by global CDS shocks. Będowska-Sójka and Kliber (2013) confirmed the strong interrelationship that exists between foreign exchange and sCDS on the Polish market.

Our article contributes to the existing literature in the following way. First, we analyse the possible causality from SCDS market to other financial markets within a country, interpreting the results as the degree of immunity against volatility transmission or herd behaviour. Second, we analyse the role of the new regulations from November 2012 on the strength of those relationships, extending the study of Kliber (2016) and Kliber (2017), where the influence of the global factor had not been taken into account. We end our sample in 2013, i.e. the year in which another regulation came into force - the Title VII of the Dodd-Frank Wall Street Reform and Consumer Protection Act (see: ISDA 2015). We believe that if we considered longer periods, we would be unable to distinguish between the effect of the two different regulations.

The structure of the paper is as follows. First, we present the data and briefly describe the four segments of the financial markets in the five countries under analysis. Next, we present the results of the VAR and Granger-causality analysis for the returns. Finally, we discuss the estimation of the volatility models and the results of the causality-in-variance tests. We end our article with a discussion of the results. 


\section{METHODOLOGY}

We commenced our research with the performance of stationarity tests for each data series (KPSS and ADF) - see Table 1 in the Appendix for the results. As each series proved to be non-stationary, we modelled changes of the series for sCDS, bonds, exchange rates, and logarithmic changes for the stock indices. In the first step of the research we estimated VAR(1) models to describe interdependencies in the conditional mean. The length of the lags in a VAR model was selected on the basis of the Schwarz information criterion, and in each case it was set to 1 . To be able to take into account the influence of the so-called "global factor", we included the changes of the German 10-year yield bonds in the equation as an exogenous variable. Next, we ran the Granger causality test to find the direction of information transmission between the markets in each country. The test was performed in sub-periods to analyse the possible change after the ban on naked sCDS trade.

Next, we estimated the GARCH-type models for residuals. Using the standardised residuals, we performed yet another test - for causality in variance proposed by Hong (2001), which is an extension of the noncausality test of Cheung and $\mathrm{Ng}$ (1996).

\subsection{Non-causality test of Cheung and Ng}

Let us consider two stationary and ergodic time series processes: $X_{t}$ and $Y_{t}$, as well as two information sets defined by: $I_{t}=\left\{X_{t-j}, j \geq 0\right\}$ and $J_{t}=\left\{X_{t-j}, Y_{t-j}, j \geq 0\right\} . Y_{t}$ is said to cause $X_{t+1}$ in variance if

$$
E\left[\left(X_{t+1}-\mu_{x, t+1}\right)^{2} \mid I_{t}\right] \neq E\left[\left(X_{t+1}-\mu_{x, t+1}\right)^{2} \mid J_{t}\right],
$$

where $\mu_{x, t+1}$ is the conditional mean of $X_{t+1}$ (conditioned on $I_{t}$ ). Feedback in variance occurs when $X_{t}$ causes $Y_{t}$, and $Y_{t}$ causes $X_{t}$.

Let us also suppose that:

$$
\begin{gathered}
X_{t}=\mu_{x, t}+h_{x, t}^{0,5} \epsilon_{t}, \\
Y_{t}=\mu_{y, t}+h_{y, t}^{0,5} \xi_{t} .
\end{gathered}
$$


In the model above, $\mu_{z, t}$ denotes the conditional mean of process $Z, h_{z, t}-$ the conditional variance, of process $Z$, while $\epsilon_{t}$ and $\xi_{t}$ are white noise processes with the null mean. Let $U_{t}$ and $V_{t}$ denote squares of standardised residuals:

$$
\begin{gathered}
U_{t}=\frac{\left(X_{t}-\mu_{x, t}\right)^{2}}{h_{x, t}}=\epsilon_{t}^{2}, \\
V_{t}=\frac{\left(Y_{t}-\mu_{y, t}\right)^{2}}{h_{y, t}}=\xi_{t}^{2} .
\end{gathered}
$$

Let $r_{U, V}(k)$ denote cross-correlation between $U$ and $V$, for the $k$-th lag:

$$
r_{U, V}(k)=\frac{c_{U, V}(k)}{\sqrt{\left(c_{U, U}(0) c_{V, V}(0)\right)}},
$$

where $c_{U, V}(k)$ denotes covariance between $U$ and $V$ at lag $k$. Since the processes $U$ and $V$ are independent:

$$
\left[\begin{array}{l}
\sqrt{T} r_{U, V}(k) \\
\sqrt{T} r_{U, V}\left(k^{\prime}\right)
\end{array}\right] \sim N\left(\left[\begin{array}{l}
0 \\
0
\end{array}\right],\left[\begin{array}{ll}
1 & 0 \\
0 & 1
\end{array}\right]\right), \quad k \neq k^{\prime} .
$$

Cheung and $\mathrm{Ng}$ proposed the following test for causality in variance. First, we form the following statistic:

$$
S=T \sum_{i=j}^{k} \hat{r}_{U, V}^{2}(i) \sim \chi^{2}(k-j+1) .
$$

With a small sample, the authors propose the following weighted statistic:

$$
S=T \sum_{i=j}^{k} \widehat{\omega_{i}} \widehat{r_{U, V}^{2}}(i)
$$

where $\omega_{i}=\frac{T+2}{T-|i|}$. The statistics are used to test the null hypothesis of no causality in variance. 


\subsection{Non-causality test of Hong}

Hong (2001) modified the test statistic (1), pointing out that a larger weight should be attributed to more recent correlations. The idea of the test is as follows: volatility tends to cluster, which means that high volatility on day $t$ tends to be followed by another high volatility on day $t+1, t+2, \ldots, t+n$. The same holds for low-volatility days. Usually also high volatility on day $t+1$ has a bigger impact on volatility on day $t$ than volatility on day $t+n$, where $n$ is a day in the distant past. Empirical studies suggest that the impact of very distant volatility is rather negligible. Thus, the Cheung and $\mathrm{Ng}$ (1996) test may be inefficient if big $M$ is used, because of the equal weighting of even distant correlations. On the other hand, some financial time series indeed exhibit strong cross-correlations and in such cases tests based on a small number of past correlations may fail to detect causality. Thus, it is advisable to let $M$ grow with $T$ or include all $T-1$ crosscorrelations (with correspondingly diminishing weights).

The Hong statistic has the following form ${ }^{1}$ :

$$
Q=\frac{S_{H}(k)-C_{i, T}(k)}{D_{i, T}(k)} \sim N(0,1),
$$

where:

$$
\begin{gathered}
S_{H}(k)=T \sum_{i=1}^{T-1} k^{2}\left(\frac{i}{M+1}\right) r_{U, V}^{2}(i), \\
C_{i, t}(k)=\sum_{i=1}^{T-1}\left(1-\frac{i}{T}\right) k^{2}\left(\frac{i}{M+1}\right), \\
D_{i, T}(k)=\sum_{i=1}^{T-1}\left(1-\frac{i}{T}\right)\left(1-\frac{(i+1)}{T}\right) r_{U, V}^{4}(i) .
\end{gathered}
$$

The variables $C_{i, t}(k)$ and $D_{i, t}(k)$ are approximately a mean and a variance of $S_{H}$, while $M$ is a positive integer, denoting the lag truncation order, while $k(z)$ is the weighting function. Let us emphasise that $S_{H}$ in (4)

\footnotetext{
${ }^{1}$ Following Osińska $(2008,2011)$ and Łęt (2012), we use a slightly modified version of the statistic, putting in the denominator $(M+1)$ instead of $M$ in order to have non-zero weight for the $M$-th correlation.
} 
is a special case of (2), where $\omega_{i}=k^{2}\left(\frac{i}{M+1}\right)$. Hong (2001) proposed several weighting functions $k(\cdot)$ : the truncated, Bartlett, Parzen and TuckeyHanning kernels, which attribute 0 weights to lags greater than $M$, as well as Daniell and QS (quadratic-spectral) that have the so-called unbounded support. Below we present the formulas of the Daniell and Tuckey-Hanning kernels:

$$
\begin{gathered}
k(z)=\frac{\sin (\pi z)}{\pi z}-\text { Daniell kernel, } \\
k(z)=\left\{\begin{aligned}
0.5(1+\cos (\pi z)), & |z| \leq 1 \\
0, & \text { otherwise }
\end{aligned}\right. \text { - Tuckey-Hanning kernel. }
\end{gathered}
$$

The $Q$ statistic is normally distributed and it should be compared to the upper-tailed critical value of $\mathrm{N}(0,1)$. If $Q$ is larger than the critical value, the null hypothesis about non-causality should be rejected.

\section{THE DATA}

We collected the data of the 5-year euro-denominated SCDS (data source: Thomson Reuters Datastream), bonds, exchange rates, and the indices for five countries that retained their own currencies up to the end of 2013, i.e. the Czech Republic, Hungary, Poland (the so-called V3 group), as well as Sweden and the United Kingdom (the developed markets of Western Europe). To approximate the European risk, i.e. a common factor that influences all the financial markets together, we used the German 10-year yield bonds. Such an approach is justified in the literature - see e.g. Coudert and Gex $(2010,2011)$ and O'Kane (2012). If we had disregarded the global factor we could have obtained spurious results of causality and misleading conclusions.

\subsection{Bond market}

The domestic bonds market is documented as being the most isolated from the incidents abroad (Kocsis, 2014). Let us compare the dynamics of the sCDS spreads together with the dynamics of the sovereign bonds yields: see Figures 1 to 5 . When we analyse Figures 1 to 5 we can see that the only case when the SCDS spread and yield changed in the same direction in the 
whole period was Hungary (Figure 4) - the riskiest market of all the analysed economies. For Poland (Figure 2a) and the Czech Republic (Figure 2b) such a pattern can be observed since 2011, while in the case of Sweden (Figure 1a) and the UK (Figure 1b) the changes went in the opposite directions, indicating that the countries were considered safe by investors (as already mentioned in the literature review section, investors favour safe assets, so in a period of distress the yield of safe bonds lowers, while the yield of the risky ones increases; at the same time sCDS spreads grow, too, hence the correlation between the yield of sovereign bonds and SCDS spreads should be positive for risky and negative for safe bonds).
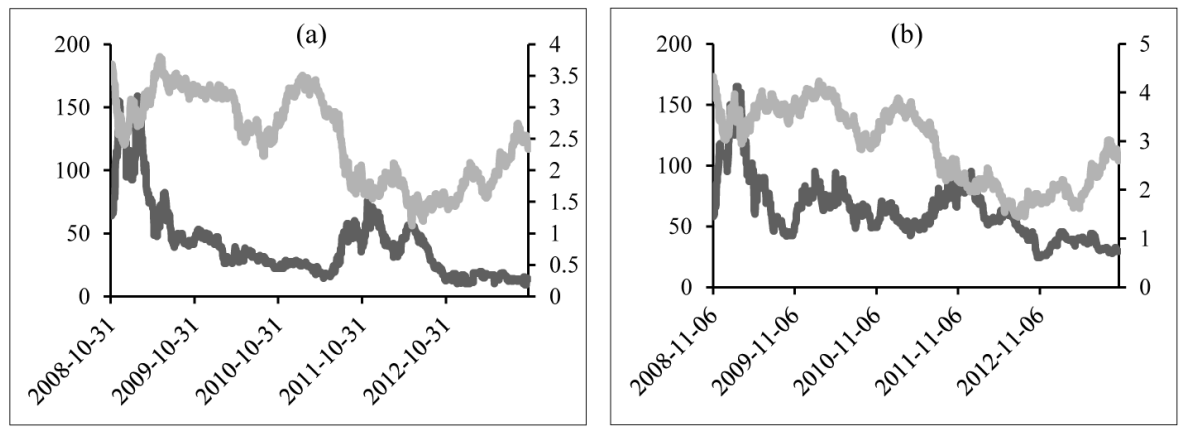

Fig. 1. Dynamics of sCDS (left axis, black line) and bonds (right axis, grey line) Sweden (a) and the United Kingdom (b)

Source: author's own.
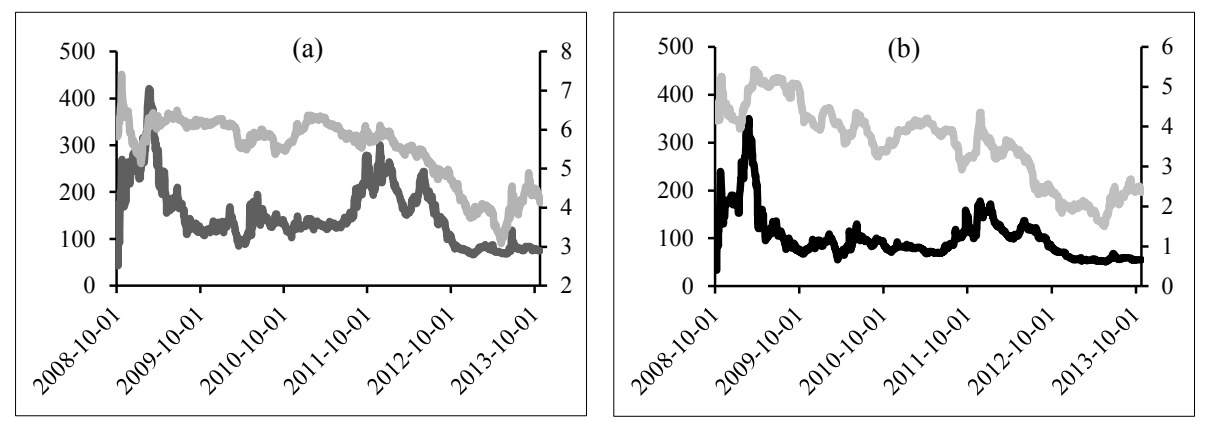

Fig. 2. Dynamics of sCDS (left axis, black line) and bonds (right axis, grey line) - Poland (a) and the Czech Republic (b)

Source: author's own. 
When we compare the dynamics of the sCDS series among the countries we can also observe that for Sweden and the UK the reaction of spreads to the onset of the crisis was much stronger than the reaction to the Greek problems that followed in 2011. As for the V3 group (Figures 2 and 3), the increase of the sCDS spreads in 2011 was sharper than in the case of the UK and Sweden - however, this reaction is indistinguishable from the reaction to the Hungarian problems in 2011.

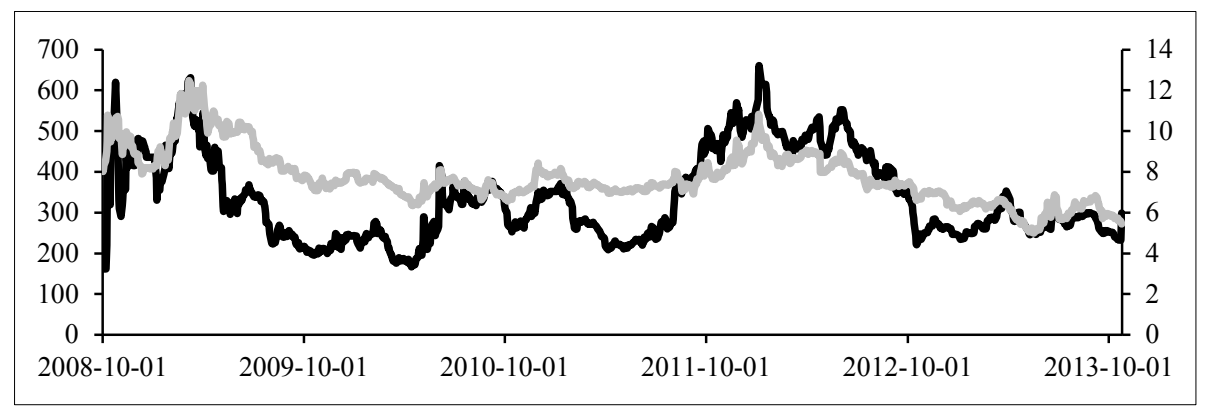

Fig. 3. Dynamics of sCDS (left axis, black line) and bonds (right axis, grey line) Hungary

Source: author's own.

\subsection{Exchange rate}

All of the analysed countries retained their own currencies up to the end of 2013. However, each of the countries had their own exchange rate policy. For example, in the United Kingdom, Sweden, Poland, and the Czech Republic the exchange rate regime was free floating, and for Hungary floating.

In Sweden and Great Britain (Figure 4) the trend was constantly upward, which seems to be contradictory to SCDS changes. The drop of SEKEUR and GBPEUR is accompanied by the growth of CDS - the periods of depreciation correspond to the periods of the country's risk growth.

In the case of the Czech Republic, Poland, and Hungary we can see a significant drop at the end of 2008 and at the beginning of 2009 (Figures 5 and 6). The point when the drop overlaps with the point of the increase of sCDS premiums is the moment the financial crisis in Europe began, launching speculative attacks on the Central-European currencies. Due to the crisis transmission and speculative attacks on the East-European currencies, depreciation is discernible in all three instances. When it comes to Poland 
and Hungary, we can also observe a second episode of the exchange rate decrease, which overlaps with the sCDS increase at the end of 2011. This event can be attributed to the speculative attack on the zloty and the forint, partially due to the Greek crisis. The decrease in the Czech koruna exchange rate was not significant.
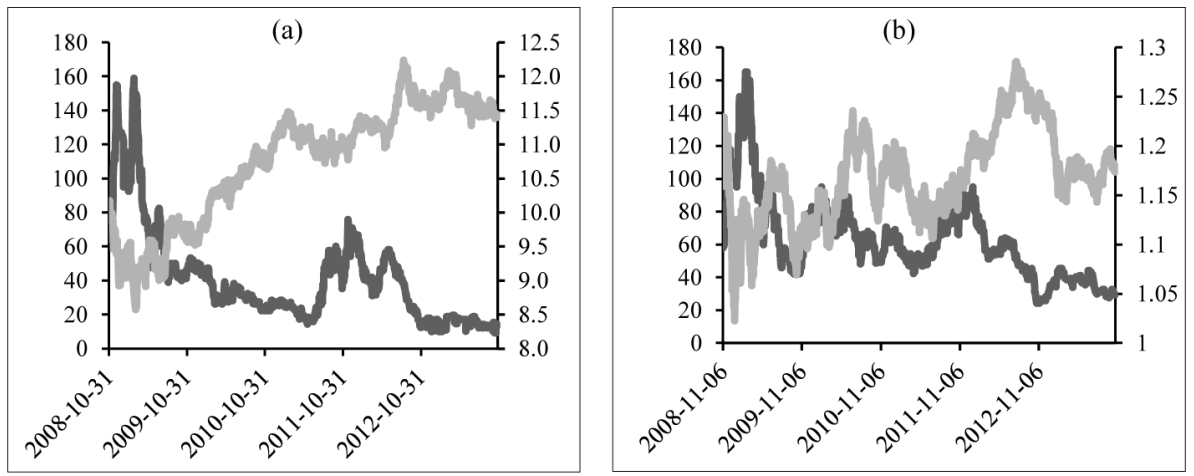

Fig. 4. Dynamics of the Swedish sCDS (left axis, black line) versus SEKEUR (right axis, grey line) exchange rate - panel (a) and the British sCDS (left axis, black line versus GBPEUR (right axis, grey line) - panel (b)

Source: author's own.
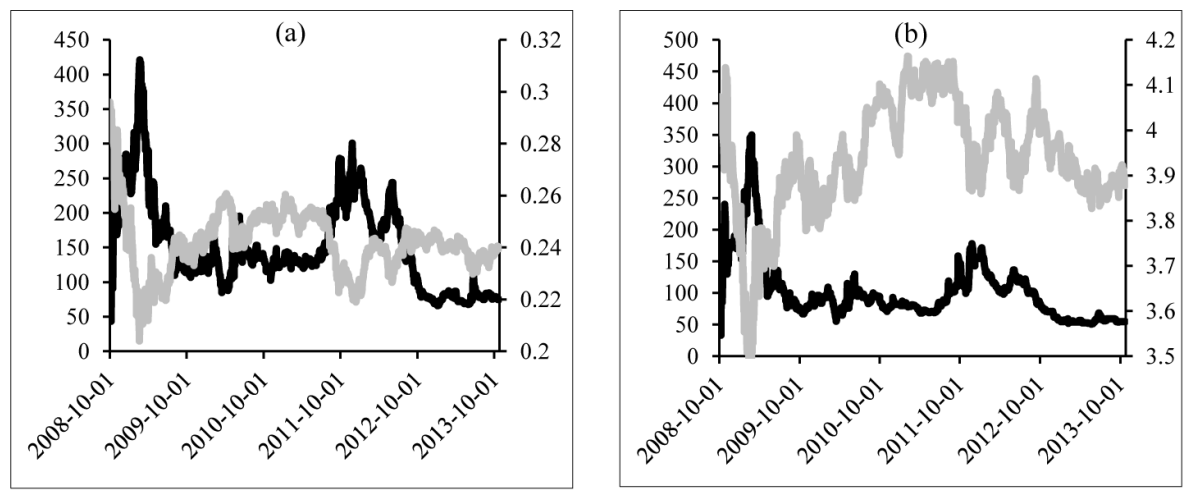

Fig. 5. Dynamics of the Polish sCDS (left axis, black line) versus PLNEUR (right axis, grey line) - panel (a) and the Czech sCDS (left axis, black line) and CZKEUR (right axis, grey line) exchange rate - panel (b)

Source: author's own. 


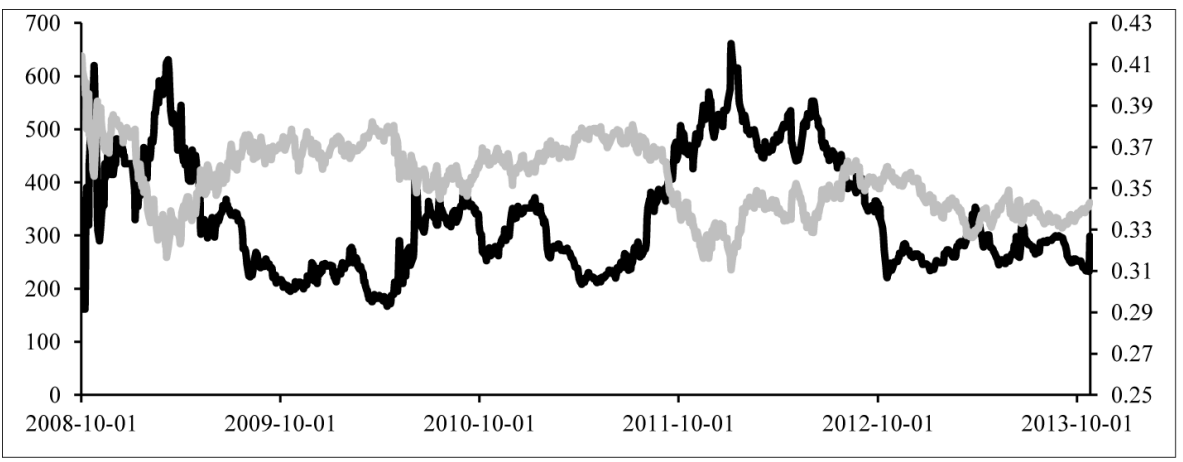

Fig. 6. Dynamics of the Hungarian sCDS (left axis, black line) and HUFEUR (right axis, grey line) exchange rate

Source: author's own.

\subsection{Stock exchange}

As far as Sweden is concerned (Figure 7a) we take into account the OMXS30 index: the OMX Stockholm 30 Index which is a price return index, comprising 30 shares which have the largest volume of trading. It is calculated in Swedish krona (NASDAQ OMX, 2014). For the United Kingdom (Figure $7 b$ ) we analyse the FTSE250 index, which represents mid-cap stocks traded on the London Stock Exchange. The index is calculated on the basis of the
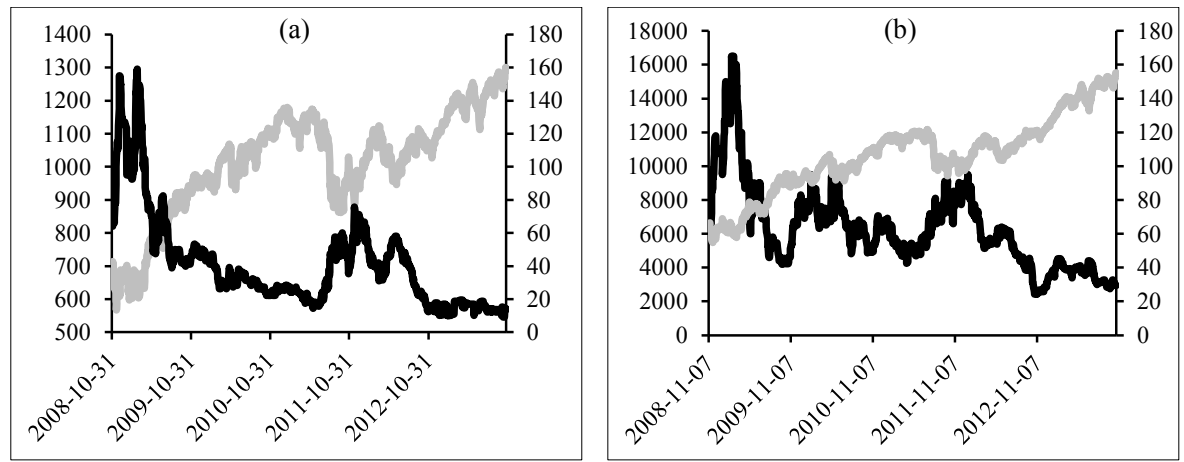

Fig. 7. Dynamics of OMXS30 (left axis, grey line) versus Swedish sCDS (right axis, black line) - panel (a) and FTSE250 (left axis, grey line) versus British sCDS (right axis, black line) - panel (b)

Source: author's own. 
price and total return methodologies: both real time, intra-second, and endof-day (FTSE Group, 2015). As regards Poland, we study the dynamics of the WIG20 index (Warsaw Stock Exchange Index), i.e. the price index comprising 20 major and most liquid companies in the WSE Main List (Figure 8a). In the case of the Czech Republic (Figure 8b) we investigate the PX index, the price index of blue chips issued on the Prague Stock Exchange (PSE, 2014). With respect to Hungary (Figure 9), we analyse the BUX: the official index of blue-chip shares listed on the Budapest Stock Exchange (http://bse.hu/). The index is a total return one, i.e. taking into account dividend payments and consists of varying number of shares, up to 25 .
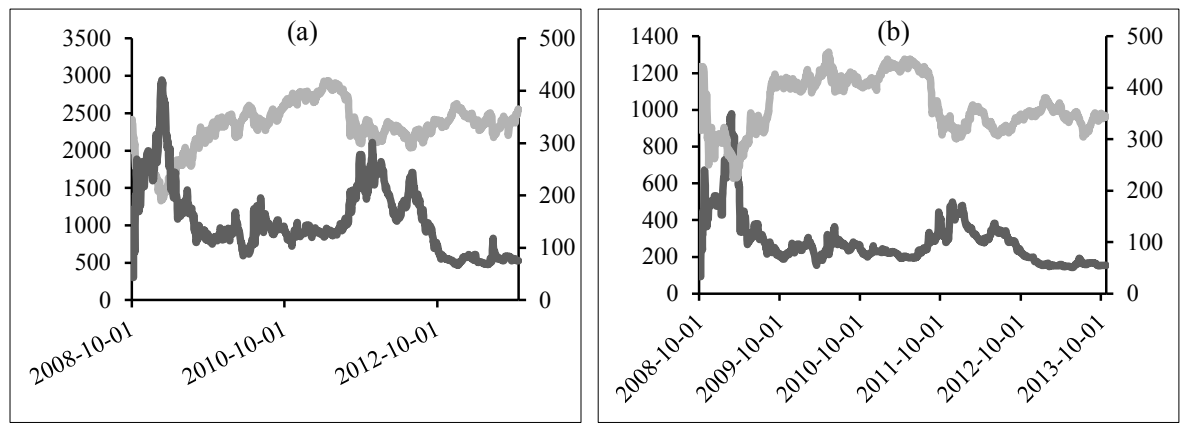

Fig. 8. Dynamics of WIG20 (left axis, grey line) versus Polish sCDS (right axis, black line) - panel (a) and the dynamics of PX (left axis, grey line) versus the Czech sCDS (right axis, black line) - panel (b)

Source: author's own.

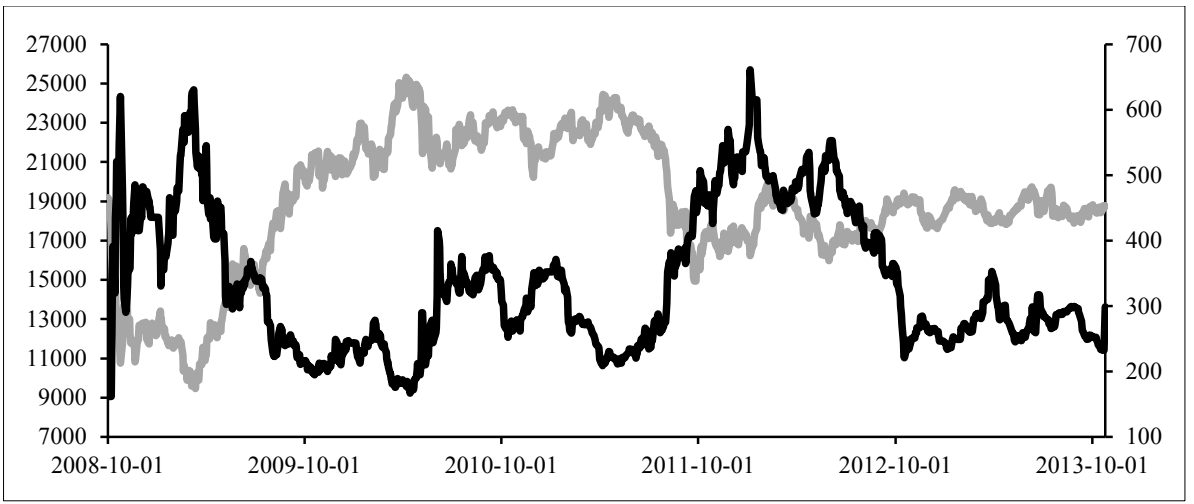
line)

Fig. 9. Dynamics of BUX (left axis, grey line) and Hungarian sCDS (right axis, black

Source: author's own. 
Figures 7 to 9 present the dynamics of the CDS series together with the stock indices. In all of the analysed cases the dynamics was similar, but the changes went in the opposite directions. The values presented in the charts are the close values of the indices and the close values of the sCDS contracts (in basis points). The relationships between the measures are intuitive - the increase of the index value is considered a positive phenomenon, thus the risk of the country should diminish. The decline of the index value is considered negative information, therefore it should be accompanied by the growth of the risk of the country.

\section{DEPENDENCIES IN THE MEAN}

First, we estimated VAR(1) models to describe interdependencies in the conditional mean. The length of lags in the VAR model was chosen based upon the Schwarz information criterion, and in each case it was set to 1 . To take into account the influence of the so-called "global factor", we included the changes of the German 10-year yield bonds as an exogenous variable in the equation. The global factor proved to be significant in all instances except for the Polish bond market, while the influence of the lagged sCDS was observed in Hungary (all equations) and the Czech Republic (bonds and stock markets).

Then, we estimated VAR(1) models for the subperiods: the first one covered the data up to 1 November 2012, while the second one was from November 2012. Next we ran the Granger causality tests for each subperiod. For the sake of consistency we do not present the results of the VAR estimation (they are available upon request), but the authors concentrate on the causality patterns. The results are presented in Table 2, while the details ( $p$-values obtained for each country in each subperiod) are presented in Table 4 in the Appendix. According to the null hypothesis there was no causality from sCDS to the system of the remaining variables.

Table 2

Causality in the mean - results

\begin{tabular}{c|l|c|c|c|c|c}
\hline $\begin{array}{c}\text { Causality } \\
\text { type }\end{array}$ & Period & Sweden & UK & Poland & $\begin{array}{c}\text { Czech } \\
\text { Republic }\end{array}$ & Hungary \\
\hline \multirow{2}{*}{ Granger } & Before 2012 & NO & NO & NO & YES & YES \\
\cline { 2 - 6 } & After 2012 & NO & NO & NO & NO & YES \\
\hline \multirow{2}{*}{ Feedback } & Before 2012 & YES & YES & YES & YES & YES \\
\cline { 2 - 6 } & After 2012 & NO & YES & YES & YES & YES \\
\hline
\end{tabular}

Source: author's own. 
In bold are the cases in which the change of interdependencies has been observed, namely Sweden and the Czech Republic. For Sweden, feedback between sCDS and other financial markets was detected, while no such relationship existed after November 2012. For the Czech Republic, Granger causality was observed up to October 2012, and no causality - from November 2012. In the case of all the other economies the relationships did not change.

However, when considering the causality patterns, a clear distinction between the economies can be made. For Sweden, the UK and Poland no Granger causality from the sCDS market is observed, which may indicate that the economies were relatively immune to the influence of turbulence from abroad already in 2012. Thus, only in the case of the Czech Republic, the introduction of the new legislation seems to have had the intended result - i.e. it made the Czech financial market more immune to speculative manipulation.

\section{DEPENDENCIES IN CONDITIONAL VARIANCE}

As in the financial markets, the relationships in volatility are even stronger than in the mean (although volatility itself is not even observed), therefore the authors decided to check the causality in variance as well, and estimated the univariate volatility models of the GARCH-type (Bollerslev, 1986) for each series in each country. The Hong test on the squared standardised residuals obtained in this way was performed, choosing the best model based upon its ability to explain all linear and non-linear dependencies of the data, as well as upon the significance and stability of the parameters. In the case of each model the authors also introduced the lagged absolute value of the change of German 10-year bond yield (an approximation of the European risk) and tested its significance. If the variable proved to be significant, it was included in the model. However, it appeared that including the global factor in the mean equation (VAR) was in many cases enough to account for the global risk. Again, for the sake of consistency the authors do not present the results of the GARCH estimation (they are available upon request), however, the authors plot the volatilities and later on concentrate on the causality models. All of the volatility models were estimated using OxMetrics7 software with G@RCH package. 


\subsection{Volatility behaviour}

Figures 10 (a) and (b) present the estimated volatilities of Swedish OMXS30, SEKEUR, bonds, and SCDS. The global factor proved to be significant only in the case of OMXS30 and SEKEUR. The CDS market seems to be the only one that did not react to the Greek problems in May 2010 , observing peaks in the volatilities of bonds, exchange rate and OMXS30, while the volatility of sCDS remained flat. This may suggest that the Swedish sCDS volatility was mostly linked to the internal situation of the country, which is quite an exceptional situation.
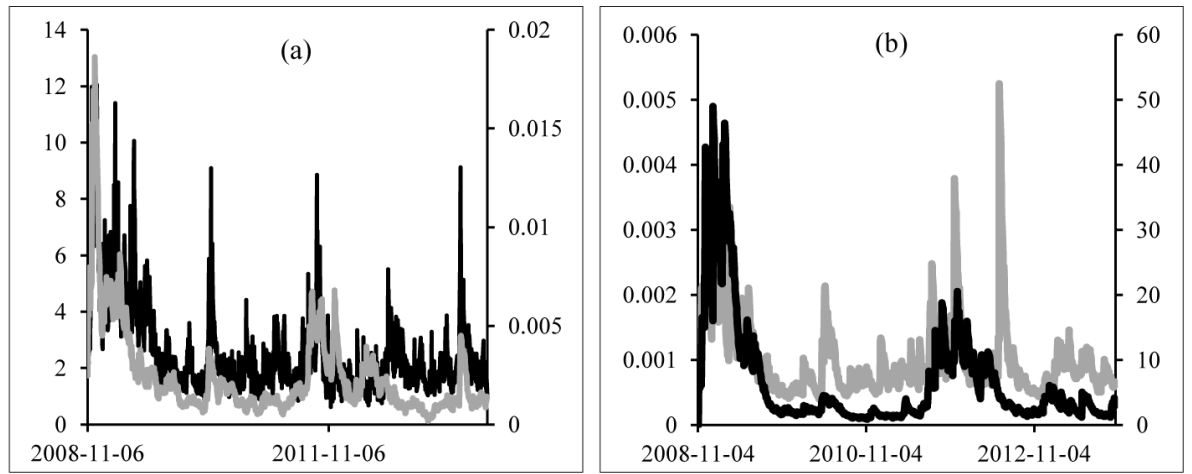

Fig. 10. Conditional variance of OMX and SEKEUR (panel (a)) and bonds and CDS (panel (b))

Note: Panel (a): black line, right axis: volatility of SEKEUR, grey line, left axis: volatility of OMX. Panel (b): black line, right axis: volatility of CDS, grey line, left axis: volatility of bonds. Only in the case of OMXS30 and SEKEUR the global factor was present in the volatility equation. In the case of OMX30, bonds and SCDS the model of conditional variance was GARCH(1,1), while in the case of SEKEUR - FIGARCH(1,1). In each case the model explained all linear and non-linear dependencies in the data and the obtained residuals were the realizations of the white noise.

Source: author's own.

In the case of the United Kingdom (Figure 11), the volatility of global factor in the conditional variance model of sCDS and FTSE was included. Volatility of bonds is much smaller and seems to be more flatted than those of the sCDS. Thus, contrary to the Swedish example, volatility of the SCDS was also linked to the international situation, while the sovereign bonds were rated by investors as safe. 

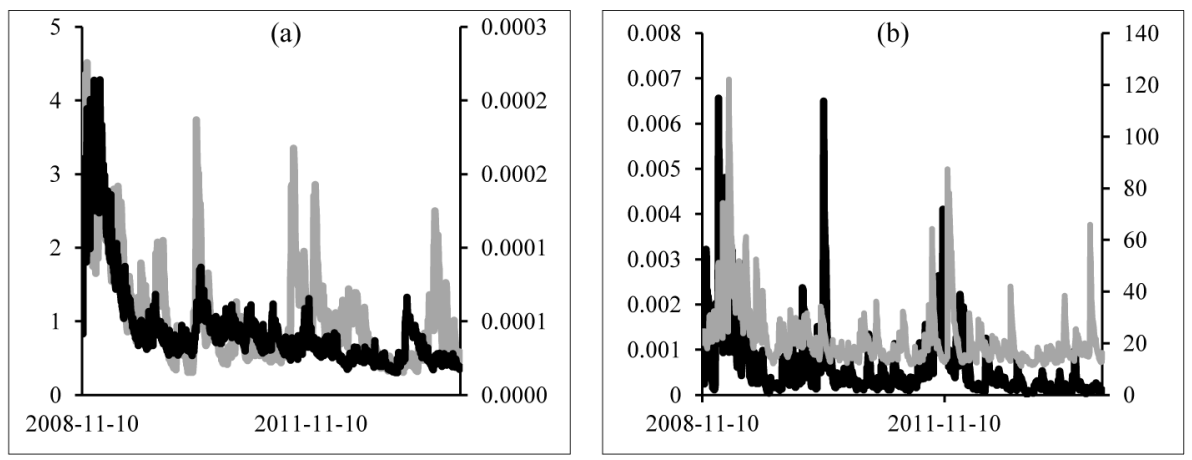

Fig. 11. Conditional variance of FTSE250 and GBPEUR (panel (a)) and bonds and CDS (panel (b))

Note: Note: Panel (a): black line, right axis: volatility of GBPEUR, grey line, left axis: volatility of FTSE. Panel (b): black line, right axis: volatility of CDS, grey line, left axis: volatility of bonds. We included volatility of global factor in the conditional variance model of SCDS and FTSE. In the case of the case of bonds, SCDS and FTSE we estimated $\operatorname{GARCH}(1,1)$ model, while in the case of GBPEUR - GARCH $(1,2)$.

Source: author's own.
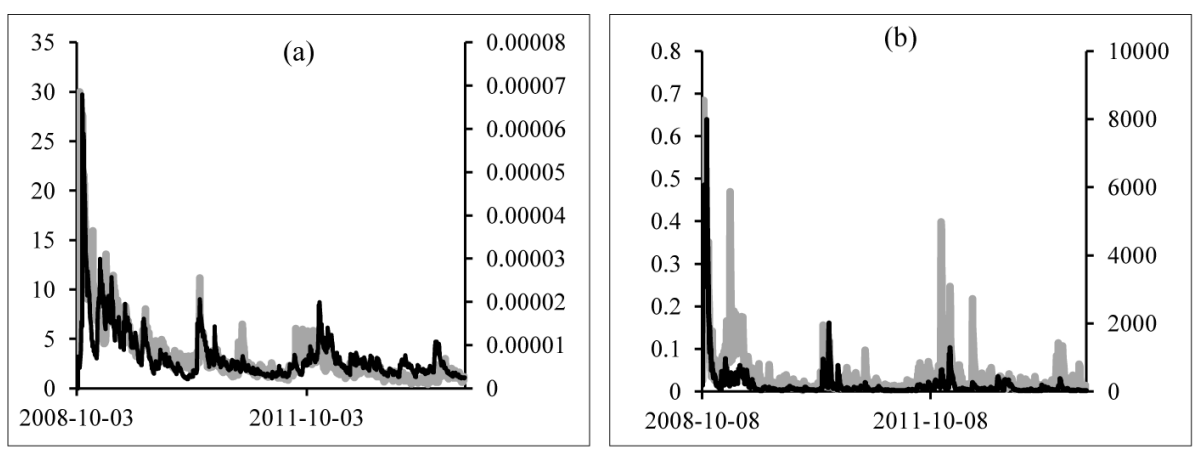

Fig. 12. Conditional variance of BUX and HUFEUR (panel (a)) and bonds and CDS (panel (b))

Note: Panel (a): black line, right axis: volatility of HUFEUR, grey line, left axis: volatility of BUX. Panel (b): black line, right axis: volatility of CDS, grey line, left axis: volatility of bonds. External regressor - volatility of global factor - proved to be significant in the volatility equation of bond and BUX. In the case of $\mathrm{SCDS}$ and HUFEUR the GARCH $(1,1)$ model was the best one, in the case of bonds - IGARCH, while in the case of BUX FIGARCH one.

Source: author's own. 

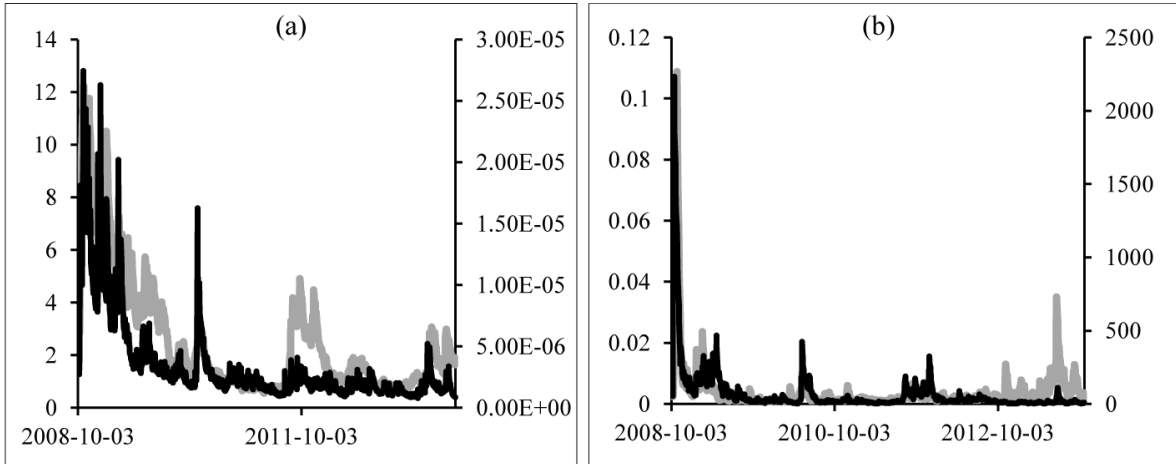

Fig. 13. Conditional variance of WIG20 and PLNEUR (panel (a)) and bonds and CDS (panel (b))

Note: Panel (a): black line, right axis: volatility of PLNEUR, grey line, left axis: volatility of WIG20. Panel (b): black line, right axis: volatility of CDS, grey line, left axis: volatility of bonds. In the case of sCDS and WIG20 volatility of global factor was introduced into the conditional variance equation. $\operatorname{GARCH}(1,1)$ was estimated as the volatility model of sCDS, bonds and WIG20, while FIGARCH $(1,1)$ - as the volatility model of PLNEUR

Source: author's own.
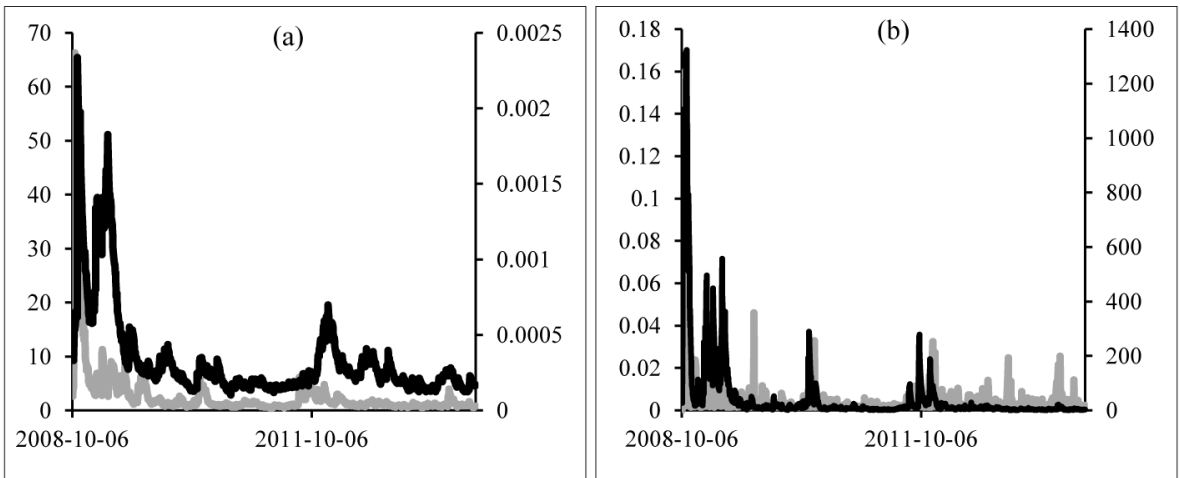

Fig. 14. Conditional variance of PX and CZKEUR (panel (a)) and bonds and CDS (panel (b))

Note: Panel (a): black line, right axis: volatility of CZKEUR, grey line, left axis: volatility of BUX. Panel (b): black line, right axis: volatility of CDS, grey line, left axis: volatility of bonds. In the case of the Czech Republic we estimated the following conditional variance models $\operatorname{IGARCH}(1,1)$ for $\operatorname{sCDS}, \operatorname{GARCH}(0,2)$ for bonds, $\operatorname{GARCH}(1,1)$ for PX and CZKEUR. Volatility of global factor was a significant explanatory variable in the volatility model of sCDS and PX.

Source: author's own. 
In the case of the V3 group (Figures 12 to 14) some similarities were discerned. First of all, the extreme growth of volatility at the beginning of the crisis was noted, due to the growing risk of crisis transmission, as well as speculative attacks on domestic currencies. One can also see a reaction to the Greek and Hungarian problems in 2010. As for Hungary (Figure 12), the global factor was significant in the volatility of bonds and BUX; for Poland (Figure 13) in the volatility of sCDS and WIG20, while for the Czech Republic (Figure 14) - sCDS and PX.

\subsection{Causality in variance}

Table 4 presents a summary of the results of the Hong test, while in Tables 5 to 9 in the Appendix the results are presented in detail. It is clear that in each country the relationships changed between the pre and post-ban period. In most cases the relationships weakened, i.e. changed from feedback to null or from feedback and Granger to feedback or null. The exception is the United Kingdom where the relationships in variance had not existed before the ban and changed to feedback with respect to the stock market only. The change from null to feedback was also observed in the case of the Czech bonds.

Table 3

Causality in variance - results

\begin{tabular}{|c|c|c|c|c|}
\hline Country & Period & Stocks & Bonds & $\begin{array}{c}\text { Exchange } \\
\text { rates }\end{array}$ \\
\hline \multirow{2}{*}{ Sweden } & Up to October 2012 & Feedback & $\begin{array}{c}\text { Feedback } \\
\text { and Granger }\end{array}$ & Feedback \\
\hline & From November 2012 & -- & Feedback & -- \\
\hline \multirow{2}{*}{ UK } & Up to October 2012 & -- & -- & -- \\
\hline & From November 2012 & Feedback & -- & -- \\
\hline \multirow{2}{*}{ Poland } & Up to October 2012 & $\begin{array}{c}\text { Feedback } \\
\text { and Granger }\end{array}$ & $\begin{array}{c}\text { Feedback } \\
\text { and Granger }\end{array}$ & $\begin{array}{c}\text { Feedback } \\
\text { and Granger }\end{array}$ \\
\hline & From November 2012 & Feedback & Feedback & Feedback \\
\hline \multirow{2}{*}{$\begin{array}{l}\text { Czech } \\
\text { Republic }\end{array}$} & Up to October 2012 & $\begin{array}{c}\text { Feedback } \\
\text { and Granger }\end{array}$ & -- & $\begin{array}{c}\text { Feedback } \\
\text { and Granger }\end{array}$ \\
\hline & From November 2012 & Feedback & Feedback & Feedback \\
\hline \multirow{2}{*}{ Hungary } & Up to October 2012 & $\begin{array}{c}\text { Feedback } \\
\text { and Granger }\end{array}$ & $\begin{array}{c}\text { Feedback } \\
\text { and Granger }\end{array}$ & Feedback \\
\hline & From November 2012 & -- & -- & -- \\
\hline
\end{tabular}

Source: author's own. 
Another noticeable thing is that before the ban the weakest relationships between the markets had been present for Sweden and the UK (mostly null or feedback only). In the case of the V3 group the relationships had been directly specified, i.e. Granger causality from sCDS market to other financial markets could be noted. This may mean that the sCDS market had incorporated information faster than other markets and that the economies had been more vulnerable to the risk of crisis transmission from abroad.

Surprisingly, once the new regulation was implemented, instantaneous causality between SCDS and the stock markets was witnessed as regards the UK, and between sCDS and bonds as regards the Czech Republic. In the UK the global factor was included in the mean and volatility equation of both instruments, thus the relationship is not a common reaction to the global risk change. Hence this result may indicate that after the ban was imposed, the volatility of sCDS responded to the same factors as the volatility of FTSE, in other words the risk of sCDS became more related to the risk of the domestic stock exchange. A similar change in relationships in the Czech Republic can be explained by referring to the change of liquidity - this was the only one of the analysed economies where liquidity of the sCDS market grew in the period from the announcement to the implementation of the ban on SCDS trade (see also the discussion below).

\section{DISCUSSION AND CONCLUSIONS}

This article compares the behaviour of the financial markets in the developing and developed European economies. The group of the developing economies comprised the V3 group: the Czech Republic, Hungary, and Poland, while the developed ones were represented by the United Kingdom and Sweden. The choice of the countries depended on whether a given country retained its own currency up to the end of 2013. The authors analysed the interdependencies between the following pairs of markets: CDS and bonds, CDS and foreign exchange, CDS and stock market, and investigated the strength of the interdependencies during the financial crisis and verified whether the ban on uncovered CDS trade could contribute to weakening of those relationships. First, the authors estimated the VAR(1) model with an exogenous variable - change of the German bond yield (an approximation of the pan-European factor), to analyse interrelations between the financial markets in each country. The next step used the residuals obtained from the model to estimate GARCH-type models 
of volatility (with a possible regressor - the volatility of the pan-European factor). The conditional variances obtained through the models allowed to standardise the residuals and to run a series of causality-in-variance tests.

The results of the study can be important for asset managers, hedging risk exposures and insurers who used to utilize sCDS as proxy hedges, as well as for governments and legislators. The results revealed that in the case of each economy a change of relationships is apparent between sCDS and other domestic financial markets - either in the mean or in volatility. In each case the relationships weakened, thus the danger of the possible destabilisation of domestic markets via the sCDS market diminished. There were, however, three exceptions: the relationships in the mean did not change in the case of Hungary, while feedback relationships in volatility arose in the case of the pairs: British sCDS-FTSE as well as Czech sCDS-Czech bonds.

Moreover, the countries differed in terms of the initial strength of the relationships and the degree of their change. Sweden and the United Kingdom displayed the weakest relationships in the pre-implementation phase. Therefore, one can suspect that the countries had been more immune than others to the sunspots and crisis transmission. When it comes to Poland, the relatively weak relationships in the mean may suggest that this country was perceived by investors as safer than the rest of the V3 group. The Czech Republic and Hungary were perceived by the investors as riskier. However, after the implementation of the ban, only feedback in the mean between sCDS and the domestic financial markets was observed in the Czech Republic, while for Hungary all the relationships in the mean remained unchanged, indicating that the sCDS market can still affect the changes of the stock indices, bond yields as well as the exchange rate.

Yet, as regards the financial markets, more dangerous are causality relationships in volatility, as the latter is not observed but strongly affects the markets. Thus, when it comes to causality in conditional variance, the relationships also weakened and therefore, the possibility of volatility spillovers from sCDS to other financial markets diminished. The most drastic change was observed for Hungary - the relationships ceased in each financial market. After the ban was imposed, the market participants could expect that the changes in Hungarian markets could be affected by the changes of sCDS prices, but that volatility from abroad would not spread to the market causing its destabilisation. Hence, the effect of the ban might have been amplified by the implementation of the domestic reforms as well as the reduction of the degree of openness of the economy. 
The differences of the results in separate economies can be contributed to various factors, among others: the liquidity of the financial markets especially sCDS and bonds, indebtedness of the country and the ratio of sCDS gross notional amount to the government debt, and the maturity of the market. Let us start from the analysis of liquidity. ISDA (2014) presents an analysis of the impact that the ban exerts on the key hedging vehicles of sovereign risk: iTraxx SovX Western Europe Index, which comprises CDS of the eurozone countries traded on Western European documentation. The authors present, inter alia, the change of the weekly average volume and trade count in the phase before the announcement of the ban in October 2011 and its implementation, as well as in the period after the implementation. When the constituents of the index are analysed, one can observe a $22 \%$ decline in the case of Sweden in the post-announcement phase and a $44 \%$ decline in the post-implementation phase, while the respective numbers for the UK amounted to $36 \%$ and $28 \%$. When we analyse the average weekly trade count, the respective numbers are: $13 \%$ and $57 \%$ for Sweden, and 35\% and $31 \%$ for the UK. However, when one concentrates on the exact numbers, the difference between the investors' interest in Swedish and British sCDS was conspicuous. For Sweden, the average weekly trade count amounted to 23 even before the announcement of the ban, while for the UK - to 107 (in the post-announcement phase: 10 and 48 respectively). The low number of transactions in the Swedish market can explain the fact that in the case of the relationships in the mean, one does not even observe any feedback between sCDS and domestic markets.

For the V3 group the change of liquidity was not so drastic. The average weekly trade count, as well as the weekly average volumes fell only in Poland and Hungary, while grew for the Czech Republic. As for the weekly average trade count, a fall from 57 to 33 (by 42\%) was observed in Poland, for Hungary - from 91 to 56 (38\%), while in the Czech Republic - growth from 6 to 9 (a 50\% increase). The latter can explain the change of the causality patterns between sovereign bonds and SCDS in the Czech market i.e. the liquidity growth contributed to the strengthening of the relationships.

Yet another factor that can explain the differences in the results is the ratio of the notional amount of sCDS to government debt. This is especially important for the relationships between sCDS and the bond markets. According to the IMF (2013) data, in advanced economies (especially larger economies and those perceived to be safe) SCDS markets are generally small when compared with the underlying government debt outstanding. Therefore, based on the results of Capponi and Larsson (2014), one can 
speculate that the demise of the sCDS market would have little effect on the underlying bond market. In the case of the Czech Republic and Poland the ratio was lower than $20 \%$, which is a result typical rather for more advanced economies or those perceived as safe. On the contrary, for Hungary it exceeded 70\% in 2011 (IMF, 2013), and indeed, one can observe the much stronger reaction of the Hungarian market to the new regulation than in the remaining markets.

The differences in the results cannot be explained only by liquidity and sCDS market size. Liquidity dropped for sCDS of each market, apart from the Czech one. The growth of volume traded in the Czech sCDS market can partially explain the appearance of causality in variance for the sCDS-bonds pair. However, the change from no-causality to causality appeared also in UK (stock market), where liquidity decreased. According to IMF (2013), one should also differentiate between mature and emerging economies. For some advanced economies (here: the United Kingdom only) the underlying sovereign bond market is developed enough to enable short selling of sovereign bonds and investors can find an alternative, when hedging possibilities are concerned. In the mature economies, investors can easily find another hedging possibility, e.g. sCDS of large financial institutions. This may, in turn, shift the risk from sCDS to financial CDS markets which is likely to further strengthen the connectivity between these two markets in contrast to the goal of other policies (IMF, 2013). The increase of relationships between sCDS and the stock market in the UK may be an indicator of such a transfer of risk.

The obvious drawback of the study is the a priori choice of the moment separating the two sub-periods. One can suspect that something happened then that changed the relationships between the markets, but the authors did not test any alternative international events. Kliber (2016) showed that such a change in relationships happened in Hungary and Sweden during the period between the announcement of the reform and the moment of its implementation, while the ISDA (2014) study shows that liquidity was dropping gradually from the announcement to the implementation. This is especially visible in the example of Hungary - the moment of change and the moment of implementation of domestic reforms took place at roughly the same time (see also: Orlowski and Tsibulina, 2014). It is impossible to distinguish the real cause of the change. What one can state definitely is that as for stable economies of a liquid (the United Kingdom) or even illiquid sCDS market (Sweden), the possibility of volatility spillovers from sCDS to domestic markets was low even before the ban, so the ban had only a minor 
effect on the relationships between the markets. For small but relatively stable economics of immature financial markets such as Poland and the Czech Republic, the relationships stabilised on feedback ones, indicating that the changes in sCDS markets are more integrated with the changes in the domestic ones. Eventually, in the unstable economies - such as Hungary the sCDS market was used for speculation purposes and the ban contributed to the liquidity shrinkage and to lowering the possibility of volatility spillover between the markets to null, while allowing only for relationships in the mean.

\section{REFERENCES}

Arce, O., Mayordomo, S., Peña, J. I., Credit-risk valuation in the sovereign CDS and bonds markets: evidence from the euro area crisis, "Journal of International Money and Finance", 35, pp. 124-145, 2011.

Augustin, P., Sovereign Credit Default Swap Premia, “Journal of Investment Management", 12(2), pp. 65-102, 2014.

Będowska-Sójka, B., Kliber, A., Economic Situation of the Country or Risk in the World Financial Market? The Dynamics of Polish Sovereign Credit Default Swap Spreads, "Dynamic Econometric Models", 13, pp. 87-106, 2013.

Bollerslev, T., Generalized Autoregressive Conditional Heteroskedasticity, "Journal of Econometrics", 31, pp. 307-327, 1986.

Breuer, A., Sauter, O., The impact of a sovereign default within the eurozone on the exchange rate, "Applied Economics Quarterly", 58, pp. 1-18, 2012.

Capponi, A., Larsson, M., Will Banning Naked CDS Impact Bond Prices?, "Annals of Finance", 10 (3), pp. 481-508, 2014.

Carr, P., Wu, L., Theory and evidence on the dynamic interactions between sovereign credit default swaps and currency options, "Journal of Banking and Finance", 31, pp. 23832403, 2007.

Cheung, Y-W., Ng, L. K., A Causality-in-Variance Test and its Application to Financial Market Prices, "Journal of Econometrics", 72, pp. 33-48, 1996.

Coronado, M., Corzom, T. M., Lazcano, L., A Case for Europe: The Relationship between Sovereign CDs and Stock Indexes, "Frontiers in Finance and Economics", 9 (2), pp. 32-63, 2012.

Coudert, V., Gex, M., Credit Default Swap and Bond Markets: Which Leads the Other?, "Financial Stability Review, Banque de France", 14, pp. 161-167, 2010.

Coudert, V., Gex, M., The Interactions between the Credit Default Swap and the Bond Markets in Financial Turmoil, "Review of International Economics", 21(3), pp. 492-505, 2011.

Della Corte, P., Sarno, L., Schmeling, M., Wagner, C., Sovereign Risk and Currency Returns, Working Paper, available at: http://papers.ssrn.com/sol3/papers.cfm?abstract id=2354935, 2014. 
Ergunor, E. O., On the Resolution of Financial Crises: The Swedish Experience, "Policy Discussion Papers", 21, 2007.

Fontana, A., Scheicher, M., An Analysis of Euro-Area Sovereign CDS and their Relation with Government Bonds, "European Central Bank Working Paper" no 1271, 2010.

Fontana, A., Scheicher, M., An analysis of euro area sovereign CDS and their relation with government bonds, "Journal of Banking and Finance", 62, pp. 126-140, 2016.

FTSE Group FTSE 250 Index, "FTSE Factsheet", 2015.

Hong, Y., A Test for Volatility Spillover with Application to Exchange Rates, "Journal of Econometrics", 103, pp. 183-224, 2001.

ISDA Adverse Liquidity Effects on the EU Uncovered Sovereign CDS Ban, "ISDA Research Note", 2014.

ISDA The Dodd-Frank Act: Five Years On, "ISDA Research Note", 2015.

Jain, S., The Relationships between Interest Rates and Credit Spreads, "Market Realist", March 25, 2014.

Kliber, A., Influence of the Greek Crisis on the Risk Perception of European Economies, "Central European Journal of Economic Modelling and Econometrics", 5(2), pp.125-161, 2013.

Kliber, A., The Dynamics of Sovereign Credit Default Swaps and the Evolution of the Financial Crisis in Selected Central European Economies, "Finance a Uver", 64(4), pp. 330-350, 2014.

Kliber, A., Impact of the ban on uncovered sCDS trade on the interdependencies between CDS market and other sectors of financial market. The case of safe and developed versus risky and developing economies, "Comparative Economic Research", 19(1), pp. 77-99, 2016.

Kliber, A., Not As Black As It Is Painted? Influence of sCDS Market on Domestic Financial Market's Before and After the Ban on Naked sCDS Trade [in:] Jajuga, K., Orlowski, T., Staehr, K.(eds.) "Contemporary Trends and Challenges in Finance. Proceedings from the $2^{\text {nd }}$ Wroclaw Conference in Finance", 2017 (in press).

Kocsis, Z., Global, regional, and country-specific components of financial market indicators, "Acta Oeconomica", 64, pp. 81-110, 2014.

Łęt, B., Zależności przyczynowe $w$ sensie Grangera pomiędzy kursem terminowym ropy naftowej a wartościa dolara amerykańskiego [The Granger Causality Analysis Of Crude Oil Futures Price And U.S. Dollar Value], "AUNC Ekonomia” XLIII, 2, pp. 221-231, 2012.

Merton, R. C., On the Pricing of Corporate Debt: The Risk Structure of Interest Rates, "Journal of Finance", 29(2), pp. 449-470, 1974.

NASDAQ OMX, Rules for the Construction and Maintenance of the OMX STOCKHOLM 30 INDEX, Version 1.4., https://indexes.nasdaqomx.com/docs/Methodology_OMXS30.pdf, 2014.

Niedziółka, P. Kredytowe instrumenty pochodne a stabilność finansowa [Credit Derivatives and Financial Stability], Szkoła Główna Handlowa w Warszawie - Oficyna Wydawnicza, Warsaw, 2009.

Orlowski, L. T, Tsibulina, A., Integration of Central and Eastern European and the EuroArea Financial Markets: Repercussions from the Global Financial Crisis, "Comparative Economic Studies", 56(3), pp. 376-395, 2014. 
O'Kane, D., The Link between Eurozone Sovereign Debt and CDS Prices, "Bankers, Markets \& Investors", 117, pp. 29-39, 2012.

Osińska, M., Ekonometryczna analiza zależności przyczynowych [Econometric Analysis of Causal Relationships]. UMK Press, Toruń, 2008.

Osińska, M., On the Interpretation of Causality in Granger's Sense, "Dynamic Econometric Models", 11, pp. 129-139, 2011.

Platev, P., Marinova, E., The Link Between Credit Default Swaps and Stock Markets in Central and Eastern Europe, "Dialogue", 4, pp. 1-15, 2013.

PSE The Rules for the PX-Index and PX-TR Index of the Prague stock Exchange. Version 1.3, available at: http://ftp.pse.cz/Info.bas/Eng/PX_index_rules.pdf, 2014.

De Silva, P. P., Sovereign Credit Risk and Stock Markets-Does the Markets' Dependency Increase with Financial Distress?, "International Journal of Financial Studies", 2, pp. 145-167, 2014.

Tarnaczi, T., Kulcsar, E., The Comparative Risk And Performance Analysis Of the Hungarian And Romanian Exchange Indices, "Annals of Faculty of Economics, University of Oradea", 1(2), pp. 451-462, 2013.

WSE, Warsaw Stock Exchange Indices, May 2013, available at: http://www.gpw.pl/ pub/files/PDF /foldery/IndeksyGPW_0513_en.pdf, 2013.

Received: April 2017, revised: January 2018 


\section{APPENDIX}

Table 1

Results of the KPSS test

\begin{tabular}{l|c|c|c|c|c}
\hline & Sweden & UK & Poland & Hungary & Czech Republic \\
\hline CDS & 1.581 & 0.629 & 1.038 & 4.174 & 0.927 \\
\hline Bonds & 1.030 & 1.263 & 2.217 & 1.1193 & 0.761 \\
\hline Stock index & 1.974 & 1.499 & 2.349 & 2.387 & 2.100 \\
\hline Exchange rate & 1.857 & 0.575 & 0.649 & 2.273 & 2.080 \\
\hline
\end{tabular}

Note: Critical values: $0.119 ; 0.148$ and 0.218 respectively at $10 \%, 5 \%$ and $1 \%$ significance level.

Source: author's own.

Table 4

The results of the Granger causality test in the mean - p-values

\begin{tabular}{l|l|c|c|c}
\hline \multicolumn{1}{c}{ Country } & Causality from sCDS & Full sample & Sample 1 & Sample 2 \\
\hline \multirow{2}{*}{ Sweden } & Granger & 0.284 & 0.265 & 0.251 \\
\cline { 2 - 5 } & instantaneous & $<\mathbf{0 . 0 0 1}$ & $<\mathbf{0 . 0 0 1}$ & 0.149 \\
\hline \multirow{2}{*}{ UK } & Granger & 0.458 & 0.360 & 0.498 \\
\cline { 2 - 5 } & instantaneous & $<\mathbf{0 . 0 0 1}$ & $<\mathbf{0 . 0 0 1}$ & $\mathbf{0 . 0 0 3}$ \\
\hline \multirow{2}{*}{ Poland } & Granger & 0.971 & 0.903 & 0.607 \\
\cline { 2 - 5 } & instantaneous & $<\mathbf{0 . 0 0 1}$ & $<\mathbf{0 . 0 0 1}$ & $<\mathbf{0 . 0 0 1}$ \\
\hline \multirow{2}{*}{ Czech Republic } & Granger & $\mathbf{0 . 0 0 7}$ & $\mathbf{0 . 0 0 5}$ & 0.660 \\
\cline { 2 - 5 } & instantaneous & $<\mathbf{0 . 0 0 1}$ & $<\mathbf{0 . 0 0 1}$ & $<\mathbf{0 . 0 0 1}$ \\
\hline \multirow{2}{*}{ Hungary } & Granger & $<\mathbf{0 . 0 0 1}$ & $<\mathbf{0 . 0 0 1}$ & $\mathbf{0 . 0 4 3}$ \\
\cline { 2 - 5 } & instantaneous & $<\mathbf{0 . 0 0 1}$ & $<\mathbf{0 . 0 0 1}$ & $\mathbf{0 . 0 0 1}$ \\
\hline
\end{tabular}

Source: author's own. 
Table 5

Results of the Hong test for non-causality in variance for the Daniell and Tuckey-Hanning kernels and different lags; Sweden

\begin{tabular}{|c|c|c|c|c|c|c|c|}
\hline & $\begin{array}{l}\text { CAUSALITY } \\
\text { FROM CDS to: }\end{array}$ & & $\mathbf{M}=\mathbf{1}$ & $\mathbf{M}=5$ & $\mathbf{M}=\mathbf{1 0}$ & $\mathbf{M}=\mathbf{2 0}$ & $\mathbf{M}=\mathbf{5 0}$ \\
\hline \multirow{9}{*}{$\begin{array}{l}\text { Period up to } \\
\text { the end of } \\
\text { October } \\
2012\end{array}$} & \multirow{3}{*}{ OMX30S } & Daniell (Granger) & 0.536 & 0.129 & 0.010 & 0.001 & 0.009 \\
\hline & & Daniell (inst) & 0.052 & 0.022 & 0.002 & \begin{tabular}{|l|}
0.000 \\
\end{tabular} & 0.003 \\
\hline & & T-H (inst) & 0.057 & 0.072 & 0.003 & \begin{tabular}{|l|}
0.000 \\
\end{tabular} & 0.003 \\
\hline & \multirow{3}{*}{ Bonds } & Daniell (Granger) & 0.000 & 0.000 & 0.003 & 0.064 & 0.277 \\
\hline & & Daniell (inst) & 0.000 & 0.000 & 0.000 & $\mathbf{0 . 0 0 0}$ & 0.004 \\
\hline & & T-H (inst) & 0.000 & 0.000 & 0.000 & 0.000 & \begin{tabular}{|l|l|}
0.004 \\
\end{tabular} \\
\hline & \multirow{3}{*}{ SEKEUR } & Daniell (Granger) & 0.663 & 0.087 & 0.000 & \begin{tabular}{|l|}
0.000 \\
\end{tabular} & 0.000 \\
\hline & & Daniell (inst) & 0.791 & 0.272 & 0.000 & \begin{tabular}{|l|l|}
0.000 \\
\end{tabular} & \begin{tabular}{|l|l|}
0.000 \\
\end{tabular} \\
\hline & & T-H (inst) & 0.801 & 0.621 & 0.005 & \begin{tabular}{|l|}
0.000 \\
\end{tabular} & 0.000 \\
\hline \multirow{9}{*}{$\begin{array}{l}\text { Period } \\
\text { starting } \\
\text { from } \\
\text { November } \\
2012\end{array}$} & \multirow{3}{*}{ OMX30S } & Daniell (Granger) & 0.701 & 0.625 & 0.478 & 0.136 & 0.000 \\
\hline & & Daniell (inst) & 0.070 & 0.183 & 0.173 & 0.045 & 0.000 \\
\hline & & T-H (inst) & 0.055 & 0.290 & 0.547 & 0.530 & 0.000 \\
\hline & \multirow{3}{*}{ Bonds } & Daniell (Granger) & 0.063 & 0.131 & 0.230 & 0.194 & 0.001 \\
\hline & & Daniell (inst) & 0.000 & 0.000 & 0.000 & \begin{tabular}{|l|l|}
0.000 \\
\end{tabular} & 0.000 \\
\hline & & T-H (inst) & 0.000 & 0.000 & 0.000 & 0.000 & 0.000 \\
\hline & \multirow{3}{*}{ SEKEUR } & Daniell (Granger) & 0.774 & 0.732 & 0.768 & \begin{tabular}{|l|}
0.790 \\
\end{tabular} & \begin{tabular}{|l|}
0.029 \\
\end{tabular} \\
\hline & & Daniell (inst) & 0.612 & 0.685 & 0.739 & 0.774 & 0.033 \\
\hline & & T-H (inst) & 0.567 & 0.685 & 0.802 & 0.875 & 0.194 \\
\hline
\end{tabular}

Note: The null hypothesis states that there is no causality in variance between the analysed variables. In bold are the cases when the null of no causality was rejected.

Source: author's own.

Table 6

Results of the Hong test for non-causality in variance for the Daniell and Tuckey-Hanning kernels and different lags; The United Kingdom

\begin{tabular}{|c|c|c|c|c|c|c|c|}
\hline & & $\begin{array}{l}\text { CAUSALITY } \\
\text { FROM CDS } \\
\end{array}$ & $\mathbf{M}=\mathbf{1}$ & $\mathbf{M}=\mathbf{5}$ & $\mathbf{M}=\mathbf{1 0}$ & $\mathbf{M}=\mathbf{2 0}$ & $\mathbf{M}=\mathbf{5 0}$ \\
\hline 1 & 2 & 3 & 4 & 5 & 6 & 7 & 8 \\
\hline \multirow{9}{*}{$\begin{array}{l}\text { Period up to the } \\
\text { end of October } \\
2012\end{array}$} & \multirow{4}{*}{ FTSE250 } & Daniell (Granger) & 0.339 & 0.244 & 0.332 & 0.161 & 0.000 \\
\hline & & Daniell (inst) & 0.544 & 0.362 & 0.406 & 0.208 & 0.000 \\
\hline & & T-H (inst) & 0.578 & 0.378 & 0.459 & 0.419 & 0.000 \\
\hline & & Daniell (Granger) & 0.446 & 0.548 & 0.646 & 0.648 & 0.213 \\
\hline & Bonds & Daniell (inst) & 0.682 & 0.675 & 0.727 & 0.713 & 0.262 \\
\hline & & T-H (inst) & 0.698 & 0.669 & 0.718 & 0.788 & 0.364 \\
\hline & \multirow{3}{*}{ GBPEUR } & Daniell (Granger) & 0.715 & 0.789 & 0.844 & 0.862 & 0.668 \\
\hline & & Daniell (inst) & 0.800 & 0.853 & 0.887 & 0.897 & 0.721 \\
\hline & & T-H (inst) & 0.785 & 0.851 & 0.893 & 0.915 & 0.796 \\
\hline
\end{tabular}




\begin{tabular}{|c|c|c|c|c|c|c|c|}
\hline 1 & 2 & 3 & 4 & 5 & 6 & 7 & 8 \\
\hline \multirow{9}{*}{$\begin{array}{l}\text { Period starting } \\
\text { from November } \\
2012\end{array}$} & \multirow{3}{*}{ FTSE250 } & Daniell (Granger) & 0.116 & 0.259 & 0.366 & 0.183 & 0.114 \\
\hline & & \begin{tabular}{|l} 
Daniell (inst) \\
\end{tabular} & 0.000 & 0.000 & 0.000 & 0.000 & 0.000 \\
\hline & & T-H (inst) & 0.000 & 0.000 & 0.000 & 0.000 & 0.001 \\
\hline & \multirow{3}{*}{ Bonds } & Daniell (Granger) & 0.597 & 0.764 & 0.860 & 0.889 & 0.919 \\
\hline & & Daniell (inst) & 0.541 & 0.713 & 0.827 & 0.872 & 0.913 \\
\hline & & T-H (inst) & 0.521 & 0.678 & 0.797 & 0.881 & 0.973 \\
\hline & \multirow{3}{*}{ GBPEUR } & Daniell (Granger) & 0.753 & 0.782 & 0.762 & 0.364 & 0.021 \\
\hline & & Daniell (inst) & 0.777 & 0.828 & 0.813 & 0.452 & 0.034 \\
\hline & & T-H (inst) & 0.756 & 0.862 & 0.874 & 0.667 & 0.176 \\
\hline
\end{tabular}

Note: The null hypothesis states that there is no causality in variance between the analysed variables. In bold are the cases when the null of no causality was rejected.

Source: author's own.

Table 7

Results of the Hong test for non-causality in variance for the Daniell and Tuckey-Hanning kernels and different lags; Poland

\begin{tabular}{|c|c|c|c|c|c|c|c|}
\hline & & $\begin{array}{l}\text { CAUSALITY } \\
\text { FROM CDS }\end{array}$ & $\mathbf{M}=\mathbf{1}$ & $\mathbf{M}=5$ & $\mathbf{M}=\mathbf{1 0}$ & $\mathbf{M}=\mathbf{2 0}$ & $\mathbf{M}=\mathbf{5 0}$ \\
\hline \multirow{9}{*}{$\begin{array}{l}\text { Period up to the } \\
\text { end of October } \\
2012\end{array}$} & \multirow{3}{*}{ WIG } & Daniell (Granger) & 0.780 & 0.000 & 0.000 & 0.000 & 0.000 \\
\hline & & \begin{tabular}{|l|} 
Daniell (inst) \\
\end{tabular} & 0.000 & 0.000 & 0.000 & 0.000 & 0.000 \\
\hline & & T-H (inst) & 0.000 & 0.000 & 0.000 & 0.000 & 0.000 \\
\hline & \multirow{3}{*}{ Bonds } & Daniell (Granger) & 0.599 & 0.000 & 0.000 & 0.000 & 0.000 \\
\hline & & \begin{tabular}{|l} 
Daniell (inst) \\
\end{tabular} & 0.068 & 0.000 & 0.000 & 0.000 & 0.000 \\
\hline & & T-H (inst) & 0.052 & 0.000 & 0.000 & 0.000 & 0.000 \\
\hline & \multirow{3}{*}{ PLNEUR } & Daniell (Granger) & 0.000 & 0.000 & 0.000 & 0.000 & 0.000 \\
\hline & & \begin{tabular}{|l} 
Daniell (inst) \\
\end{tabular} & 0.000 & 0.000 & 0.000 & 0.000 & 0.000 \\
\hline & & T-H (inst) & 0.000 & 0.000 & 0.000 & 0.000 & 0.000 \\
\hline \multirow{9}{*}{$\begin{array}{l}\text { Period starting } \\
\text { from November } \\
2012\end{array}$} & \multirow{3}{*}{ WIG } & Daniell (Granger) & 0.770 & 0.796 & 0.803 & 0.604 & 0.736 \\
\hline & & \begin{tabular}{|l|} 
Daniell (inst) \\
\end{tabular} & 0.000 & 0.000 & 0.000 & 0.000 & 0.000 \\
\hline & & T-H (inst) & 0.000 & 0.000 & 0.000 & 0.000 & 0.000 \\
\hline & \multirow{3}{*}{ Bonds } & Daniell (Granger) & 0.688 & 0.688 & 0.606 & 0.360 & 0.268 \\
\hline & & Daniell (inst) & 0.000 & 0.000 & 0.000 & 0.000 & 0.000 \\
\hline & & T-H (inst) & 0.000 & 0.000 & 0.000 & 0.000 & 0.000 \\
\hline & \multirow{3}{*}{ PLNEUR } & Daniell (Granger) & 0.658 & 0.811 & 0.849 & 0.858 & 0.860 \\
\hline & & \begin{tabular}{|l} 
Daniell (inst) \\
\end{tabular} & 0.000 & 0.000 & 0.000 & 0.000 & 0.000 \\
\hline & & T-H (inst) & 0.000 & 0.000 & 0.000 & 0.000 & 0.000 \\
\hline
\end{tabular}

Note: The null hypothesis states that there is no causality in variance between the analysed variables. In bold are the cases when the null of no causality was rejected.

Source: author's own. 
Table 8

Results of the Hong test for non-causality in variance for the Daniell and Tuckey-Hanning kernels and different lags; The Czech Republic

\begin{tabular}{|c|c|c|c|c|c|c|c|}
\hline & & $\begin{array}{l}\text { CAUSALITY } \\
\text { FROM CDS }\end{array}$ & $\mathbf{M}=\mathbf{1}$ & $\mathbf{M}=\mathbf{5}$ & $\mathbf{M}=\mathbf{1 0}$ & $\mathbf{M}=\mathbf{2 0}$ & $\mathbf{M}=\mathbf{5 0}$ \\
\hline \multirow{9}{*}{$\begin{array}{l}\text { Period up to } \\
\text { the end of } \\
\text { October } 2012\end{array}$} & \multirow{3}{*}{ PX } & Daniell (Granger) & $\overline{0.016}$ & 0.000 & 0.000 & 0.000 & 0.000 \\
\hline & & Daniell (inst) & 0.000 & 0.000 & 0.000 & 0.000 & 0.000 \\
\hline & & T-H (inst) & 0.000 & 0.000 & 0.000 & 0.000 & 0.000 \\
\hline & \multirow{3}{*}{ Bonds } & Daniell (Granger) & 0.739 & 0.879 & 0.000 & 0.000 & 0.000 \\
\hline & & Daniell (inst) & 0.788 & 0.901 & 0.000 & 0.000 & 0.000 \\
\hline & & T-H (inst) & 0.774 & 0.891 & 0.000 & 0.000 & 0.000 \\
\hline & \multirow{3}{*}{ CZKEUR } & Daniell (Granger) & 0.748 & 0.000 & 0.000 & 0.000 & 0.000 \\
\hline & & \begin{tabular}{|l} 
Daniell (inst) \\
\end{tabular} & $\mathbf{0 . 5 3 0}$ & 0.000 & 0.000 & 0.000 & 0.000 \\
\hline & & T-H (inst) & 0.493 & 0.001 & 0.000 & 0.000 & 0.000 \\
\hline \multirow{9}{*}{$\begin{array}{l}\text { Period } \\
\text { starting from } \\
\text { November } \\
2012\end{array}$} & \multirow{3}{*}{ PX } & Daniell (Granger) & 0.094 & 0.037 & 0.145 & 0.369 & 0.533 \\
\hline & & Daniell (inst) & 0.000 & 0.000 & 0.000 & 0.000 & 0.000 \\
\hline & & T-H (inst) & 0.000 & 0.000 & 0.000 & 0.000 & 0.000 \\
\hline & \multirow{3}{*}{ Bonds } & Daniell (Granger) & 0.566 & 0.598 & 0.595 & 0.411 & 0.010 \\
\hline & & \begin{tabular}{|l|} 
Daniell (inst) \\
\end{tabular} & 0.000 & 0.000 & 0.000 & 0.000 & 0.000 \\
\hline & & T-H (inst) & 0.000 & 0.000 & 0.000 & 0.000 & 0.000 \\
\hline & \multirow{3}{*}{ CZKEUR } & Daniell (Granger) & 0.722 & 0.663 & 0.764 & 0.821 & 0.608 \\
\hline & & Daniell (inst) & 0.000 & 0.000 & 0.013 & 0.100 & 0.120 \\
\hline & & T-H (inst) & 0.000 & 0.000 & 0.006 & 0.085 & 0.279 \\
\hline
\end{tabular}

Note: The null hypothesis states that there is no causality in variance between the analysed variables. In bold are the cases when the null of no causality was rejected.

Source: author's own.

Table 9

Results of the Hong test for non-causality in variance for the Daniell and Tuckey-Hanning kernels and different lags; Hungary

\begin{tabular}{|c|c|c|c|c|c|c|c|}
\hline & & $\begin{array}{l}\text { CAUSALITY } \\
\text { FROM CDS }\end{array}$ & $\mathbf{M}=\mathbf{1}$ & $\mathbf{M}=\mathbf{5}$ & $\mathbf{M}=\mathbf{1 0}$ & $\mathbf{M}=\mathbf{2 0}$ & $\mathbf{M}=\mathbf{5 0}$ \\
\hline 1 & 2 & 3 & 4 & 5 & 6 & 7 & 8 \\
\hline \multirow{9}{*}{$\begin{array}{l}\text { Period up to } \\
\text { the end of } \\
\text { October } 2012\end{array}$} & \multirow{3}{*}{ BUX } & Daniell (Granger) & 0.028 & 0.025 & 0.175 & 0.481 & 0.779 \\
\hline & & Daniell (inst) & 0.000 & 0.000 & 0.000 & 0.000 & 0.000 \\
\hline & & T-H (inst) & 0.000 & 0.000 & 0.000 & 0.000 & 0.000 \\
\hline & \multirow{3}{*}{ Bonds } & Daniell (Granger) & 0.000 & 0.000 & 0.000 & 0.000 & 0.002 \\
\hline & & Daniell (inst) & 0.000 & 0.000 & 0.000 & 0.000 & 0.000 \\
\hline & & T-H (inst) & 0.000 & 0.000 & 0.000 & 0.000 & 0.000 \\
\hline & \multirow{3}{*}{ HUFEUR } & Daniell (Granger) & 0.724 & 0.689 & 0.824 & 0.503 & 0.567 \\
\hline & & Daniell (inst) & 0.000 & 0.000 & 0.000 & 0.000 & 0.000 \\
\hline & & T-H (inst) & 0.000 & 0.000 & 0.000 & 0.000 & 0.000 \\
\hline
\end{tabular}




\begin{tabular}{|c|c|c|c|c|c|c|c|}
\hline 1 & 2 & 3 & 4 & 5 & 6 & 7 & 8 \\
\hline \multirow{9}{*}{$\begin{array}{l}\text { Period } \\
\text { starting from } \\
\text { November } \\
2012\end{array}$} & \multirow{3}{*}{ BUX } & Daniell (Granger) & 0.690 & 0.758 & 0.625 & 0.381 & 0.037 \\
\hline & & Daniell (inst) & 0.797 & 0.837 & 0.733 & 0.491 & 0.060 \\
\hline & & T-H (inst) & 0.791 & 0.843 & 0.777 & 0.658 & 0.262 \\
\hline & \multirow{3}{*}{ Bonds } & Daniell (Granger) & 0.746 & 0.864 & 0.879 & 0.892 & 0.844 \\
\hline & & Daniell (inst) & 0.691 & 0.846 & 0.875 & 0.894 & 0.852 \\
\hline & & T-H (inst) & 0.659 & 0.815 & 0.872 & 0.915 & 0.945 \\
\hline & \multirow{3}{*}{ HUFEUR } & Daniell (Granger) & 0.769 & 0.821 & 0.888 & 0.902 & 0.662 \\
\hline & & Daniell (inst) & 0.825 & 0.877 & 0.921 & 0.928 & 0.720 \\
\hline & & T-H (inst) & 0.802 & 0.866 & 0.914 & 0.951 & 0.923 \\
\hline
\end{tabular}

Note: The null hypothesis states that there is no causality in variance between the analysed variables. In bold are the cases when the null of no causality was rejected.

Source: author's own. 